\title{
The Effect of Mental Training Program on Improving Mental Toughness among Tehran High School Student Athletes
}

\author{
Mohammad Ali Rasti ${ }^{1}$, Zainudin Bin Abubakar ${ }^{1}$, Zainal Bin Abidin ${ }^{1} \&$ Farzad Valiollah $^{2}$ \\ ${ }^{1}$ Department of Educational Psychology, University Technology Malaysia, Malaysia \\ ${ }^{2}$ Department of Educational Psychology, Kharazmi University Iran, Iran \\ Correspondence: Mohammad Ali Rasti, Department of Educational Psychology, University Technology \\ Malaysia, Malaysia. E-mail: esfehani.mohamad3@gmail.com
}

Received: October 15, 2015 Accepted: November 15, 2015 Online Published: November 23, 2015

doi:10.5539/ass.v11n28p175 URL: http://dx.doi.org/10.5539/ass.v11n28p175

\begin{abstract}
The attention to mental training program among young athletes has increased in recent decades. In spite of the significant contribution of mental toughness to perform (Jones et al., 2007), little quantitative research has been dedicated to examining this construct or to improve mental toughness. The present study investigated the effect of mental training program on mental toughness among160 participants of high school male and female student athletes. This research was experimental and the participants were selected randomly. Training consisted of one session per week. Mental toughness was assessed by SMTQ (Sheared \& Golby, 2008). Factorial MANCOVA analysis indicated that the mental training program was effective in changing the mental toughness in Tehran high school student athletes involved in different types of sport but was not effective in changing the above factor based on gender.
\end{abstract}

Keywords: mental training program, mental toughness, student athlete

\section{Introduction}

Various personality traits, mental skills, have noticeable influence on the way mental training is learned and taught (Allen et al., 2011). Common elements in teaching and learning mental training program (MTP) include individual factors and mental skills. These elements appear to be necessary for success and optimal performance. The mental skills help individuals achieve the desired goals (Gucciardi, 2008). A close investigation of mental skills and personality traits makes us familiar with individual preferences, planning and goal setting, self-control and so on. It has been observed that these skills develop in the evolution of an athlete to achieve optimal performance (Etiner, 2009). The developed mental skills distinguish the World and Olympic champions from normal athletes (Anshel, 2008). In other words, developing these skills is necessary for obtaining championship and success. Then, classifying mental abilities according to their importance, effect on mental development, and function on young and adolescent athletes seems to be of pivotal value on the grounds that MTP is more useful for young athletes than adult ones (Etiner's, 2009).

Clough and Strycharczyk (2012) considered the importance of various features of mental toughness such as considering challenges as an opportunity and self-confidence as high level of self-esteem. According to Weinberg and Gould (2003), mental skills including self-confidence, challenge power, self-control, commitment to tasks and desires, and self-control especially in difficulties need regular exercise just like the physical ones. These skills should be developed beginning in adolescence with continuous training.

Referring to other effects of mental toughness on students is not irrelevant. These effects also indicate that mental toughness can grow. Studies conducted in schools and colleges in the UK and the Netherlands show that there is a close relationship between mental toughness and performance of adolescents and young adults on tests (Clough \& Strycharczyk, 2012). These studies show that over $25 \%$ of the variation in performance on tests can be described by mental toughness. Hence, there is a possibility to develop mental toughness, which, in turn, leads to better performance on quizzes and tests (Clough, 2012). This research shows that mental toughness can define performance in terms of stress origins such as exams, and that there is a close relationship between these two.

Vealey (2002) defined the term MTP as "describing techniques and strategies designed to teach or enhance 
mental skills that facilitate performance and a positive approach to sport competition." Conducting MTP is argued to be effective in helping athletes perform better. According to Sheard and Golby (2006), a MTP that is well-planned provides an opportunity to foster the individual growth of young athletes and facilitate their growth in other areas of their lives.

Kristiansen and Robert (2010) proposed that the role of MTP in the development of coping skills among young athletes still requires further investigation. They noted that these young competitors are subject to high stress in the face of difficult Olympic and world competitions. Accordingly, they suggest that having an MTP seems necessary for this group of athletes to achieve national and international success.

According to Yoo (2000), MTP is by definition, context specific. Therefore, in the specific context in our society, the first step is deciding which mental skills are more important before setting out to plan and implement MTP for teens and youth in preparation for Olympic and World competitions.

Finally, Crust (2010) states that there is considerable amount to theoretical research on mental toughness. However, there is a large gap between theory and practice that should be bridged by future research.

\section{The Background of the Study}

Iran has achieved much success in the Olympics and world championships, especially in the last decade. Champions have endured great hardships to reach high levels. Observing their characteristics is shaping sport psychologists' experience in psychological training (Etiner, 2009). They are good models for teenagers and young athletes. Finding a practical model of them for young athletes is critical in the course of further development. That is why Etiner (2009) believes that MTP has a greater effect on adolescents rather than adults since they are more prepared for positive mental changes. However, adults have a more established mental state with either positive or negative mental patterns. Assuming that mental matters are as important as physical and tactical ones, and then mental toughness as an important psychological factor should be investigated (Crust \& Azadi, 2010).

On the other hand, Etnier (2009) considers mental toughness as a general concept which is built with the help of mental skills. The components of mental toughness, e.g., self-confidence and control grow through mental training (Sheard \& Golby, 2006). Etnier (2009) considers mental toughness as an umbrella term describing personal characteristics with the best performance in dealing with stress, distractions, and even misfortune. This is the simplest definition of mental toughness.

Referring to other effects of mental toughness and coping on students is not irrelevant. These effects also indicate that mental toughness can grow. Studies conducted in schools and colleges in the UK and the Netherlands show that there is a close relationship between mental toughness and performance of adolescents and young adults on tests (Clough \& Strycharczyk, 2012). These studies show that over $25 \%$ of the variation in performance on tests can be ascribed to mental toughness. Hence, there is a possibility to develop mental toughness, which, in turn, leads to better performance on quizzes and tests (Clough, 2012). This research shows that mental toughness can define performance in terms of stress origins such as exams, and that there is a close relationship between these two.

In addition, in Sheard and Golby's study (2006) based on 36 swimmers at national level, the mental training program was reported to have had a positive effect on the performance of the participants. The swimmers also stated that the program had been effective in other areas of their life such as school and human communication. However, a critical question is whether the interventional program was designed only for mental toughness or took a practical approach in order to upgrade a particular group of mental skills to overcome adversity and improve the coping capabilities (Connaughton et al., 2008). Yet, other research suggests that MTP have a positive impact on visualization which facilitates the development of the conceptual components of mental toughness such as self-confidence (Sheard, 2010).

Although Clough (2012) insisted that mental preparation for competition must be individualized and based on the intrinsic properties, individual mental training in team sports should be merged with the mental training of the team as a whole. Howland (2010), in a study dealing with how young swimmers' cope with pressures of competition, concluded that most swimmers describe a slightly higher use of coping abilities in competition compared to practice. More experienced swimmers, on the other hand, do not use coping abilities as frequently as others.

Mental toughness is one of the mental abilities that play an important role in sports and should receive more attention and consideration (Cohen, 2013, among others). The progress made in psychology means that psychologists have developed approaches to overcome the psychological problems of athletes. These 
developments include techniques to boost confidence and deal with stressful and emotionally challenging circumstances during or after a game (Cohen, 2009). Psychological practice, along with physical exercise, is argued to have an important effect on the preparation of athletes to help them perform effectively in competitive events (Zandi \& Menati, 2013).

In terms of learning activities, Sheard and Golby (2006) provided support for the effective role of MTP in the development of mental toughness for athletes. They suggested that MTP could increase the level of self-reported mental toughness among athletes.

Resvani (2013) conducted a study exploring the effect of a MTP on mental toughness and sport performance among female futsal players in Iran. The finding indicated that MTP can increase mental toughness and sport performance. Moreover, the effect of the intervention was reported to be permanent in the follow-up stage, as well.

Kashani (2010) conducted a study in Iran that compared the mental toughness of male and female athletes in contact sports such as taekwondo, wushu, kick-boxing, and non-contact sports such as badminton, tennis, and squash, at three levels of beginner, non-elite, and elite. They found that mental toughness was significantly higher for males than females and also higher for elite athletes.

The effect of a MTP on a set of mental skills and the performance of adolescent female taekwondo athletes from the Iranian National Team was studied by Khanjari (2012) using a MTP. The results of this study showed a significant difference between the control and experimental groups in terms of their skills.

Dolat-Abadi and Bahram (2012), for example, conducted a study to determine confidence-related factors for Iranian female gymnasts at the early stages of their athletic career and found that social supports served as a reliable factor in determining confidence at the level of elementary school. Social support was defined as the admiration the gymnast receives from others. They found that as confidence levels rose, their performance was less affected by social supports and admiration as their confidence was internalized. Likewise, Clough et al. (2002) considered confidence to be a special feature of mental toughness. Sports confidence, as defined by Navabinezhad (2000), is an athlete's belief in his or her ability to achieve success.

Anshel et al. (2001) believed that psychological problems and shortcomings, not mistakes or physical shortcomings, are the culprits responsible for the weakening of an athlete. Weinberg and Butt (2011), likewise, considered psychological factors as the reason for fluctuations and inconsistencies in athletic performance. Similarly, Martins et al. (2010) concluded that the employment of mental skills brought about significant improvements in the performance of professional, Olympic, and college athletes. In a study of professional football athletes, Jang et al. (2002), for instance, found that excellent physical performance and mental skills are required to achieve a desirable level of performance. In addition, athletes with different levels of performance would likely have differing levels of mental skills. Therefore, defining the determination and mental factors that influence football athletes would provide insightful information on how to best prepare them for competitions.

Sheard and Golby (2006) confirmed the positive influence of MTP on swimming performance and a whole profile of mental skills. Jin (2004), also, explored the effect of an MTP on gymnastics performance and the development of mental skills among ten female national gymnasts. The findings indicated that the MTP had noticeable influence on imagery, relaxation, concentration, and re-concentration. Moreover, the ten gymnasts subjected to the MTP displayed a five percent improvement in their performance in competitions compared with those who did not take part in the program.

Weinberg and Williams (2001) reviewed 45 studies and reported that the positive effects of MTP on athletic performance had been observed in 38 of the cases. Along the same line, Freigang (2002) found that there was a significant influence of timed MTP on the self-efficacy of elite college swimmers. Another study on the effects of mental training techniques such as relaxation, imagery, and re-concentration, on athletes competing in the 2006 Asia games was conducted in the Iranian context by Sanati-Monfared (2006). The results indicated that there was an improvement in the concentration and self-confidence of the athletes.

In martial arts, which have their roots in East Asian cultures, the underpinning philosophy is to enhance the relationship between the mind and the body through movement and exercise (Anshel, 2008). Therefore, martial arts have an indispensable link with psychology, and, as such, the importance of using mental skills to improve the performance of practitioners is undeniable. Many competitions have been lost due to a lack of mental confidence resulting from lack of physical and technical readiness. A lack of confidence or concentration, poor self-confidence, stress, and anxiety hinder athletic performance. For many athletes, the reason for success or failure in competitions can be found, not in the outside world, but inside by examining their state of the mind. 
Hadi Saei, a taekwondo Olympic gold medalist, believes that what gives him a competitive edge is not physical or technical superiority but mental toughness (Sadogh \& Hamidi, 2011).

\section{Method}

The program was designed for all mental toughness components, including constancy, control, and confidence. This program was designed for adolescent and young student athletes. Therefore, 160 male and female athletes between 15-18 years old were randomly selected. The experimental group participants were included in this program. Eight sports, divided in two groups of four team and individual sports, were selected to be studied. The team group sports included futsal, volleyball, basketball, football, while the individual ones included ping pong, karate, taekwondo and swimming. Five players were randomly placed in each team; multiplying that into the eight sports reveals that the total number of 160 student athletes, including 40 female and 40 male student athletes, i.e. 80 student athletes formed the experimental group and 80 formed the control one.

\section{Instruments}

\subsection{The Sports Mental Toughness Questionnaire (SMTQ)}

The instrument used to collect the data was the Sports Mental Toughness Questionnaire (SMTQ) adopted from Sheard, Golby, \& Wersch (2009). The SMTQ was classified into three higher order subscales of confidence, constancy, and, control.

The SMTQ, as a standardized international instrument, was already validated and reported to enjoy a satisfactory index of internal consistency (see Sheard et al., 2009). Its reliability was re-estimated with a group of 40 student-athletes, representing the major characteristics of the population of the study. The Cronbach's Alpha index was reported to be .68 , which seems to be a satisfactory index considering the number of the items on the questionnaire.

\section{Statistical Analysis}

Data was analyzed by SPSS-23 and in the inferential procedure method, in order to generalize the results, the factorial analysis of covariance (FACTORIAL MANCOVA) was used.

Data was analyzed by SPSS-23 and in the inferential procedure method, in order to generalize the results, the factorial analysis of covariance (FACTORIAL MANCOVA) was used.

\subsection{Descriptive Analyses}

Table 1. Mean and standard deviation of the subscales of SMT

\begin{tabular}{|c|c|c|c|c|c|c|c|c|c|c|c|c|c|c|}
\hline \multirow[b]{3}{*}{ group } & \multirow[b]{3}{*}{ type } & \multirow[b]{3}{*}{ gende } & \multicolumn{6}{|l|}{ pre } & \multicolumn{6}{|l|}{ post } \\
\hline & & & \multicolumn{2}{|c|}{ confidence } & \multicolumn{2}{|c|}{ consistency } & \multicolumn{2}{|c|}{ control } & \multicolumn{2}{|c|}{ confidence } & \multicolumn{2}{|c|}{ consistency } & \multicolumn{2}{|c|}{ control } \\
\hline & & & M & S.D. & M & S.D. & M & S.D. & M & S.D. & M & S.D. & $\mathbf{M}$ & S.D. \\
\hline \multirow{4}{*}{ experimental } & \multirow{2}{*}{ individual } & Girl & 1.6 & 0.7 & 1.59 & 0.65 & 1.2 & 0.58 & 1.93 & 0.56 & 1.3 & 0.55 & 1.46 & 0.64 \\
\hline & & Boy & 2 & 0.51 & 1.15 & 0.7 & 1.76 & 0.58 & 2.15 & 0.48 & 1.06 & 0.6 & 2.1 & 0.53 \\
\hline & \multirow{2}{*}{ team } & Girl & 1.43 & 0.41 & 1.75 & 0.62 & 1.16 & 0.57 & 1.76 & 0.52 & 1.34 & 0.55 & 1.54 & 0.63 \\
\hline & & Boy & 2.1 & 0.48 & 1.21 & 0.66 & 2.13 & 0.63 & 2.35 & 0.37 & 0.91 & 0.47 & 2.39 & 0.52 \\
\hline \multirow{4}{*}{ control } & \multirow{2}{*}{ individual } & Girl & 2.04 & 0.51 & 1.11 & 0.48 & 1.63 & 0.4 & 2.03 & 0.49 & 1.11 & 0.48 & 1.63 & 0.4 \\
\hline & & Boy & 2 & 0.51 & 1.15 & 0.7 & 1.76 & 0.58 & 1.91 & 0.53 & 1.16 & 0.69 & 1.66 & 0.65 \\
\hline & \multirow{2}{*}{ team } & Girl & 2.1 & 0.53 & 1.11 & 0.71 & 1.84 & 0.71 & 2.06 & 0.49 & 1.16 & 0.67 & 1.88 & 0.67 \\
\hline & & Boy & 2.1 & 0.48 & 1.21 & 0.66 & 2.13 & 0.63 & 2.1 & 0.48 & 1.21 & 0.66 & 2.13 & 0.63 \\
\hline
\end{tabular}

Note. Q questionnaire in pretest and posttest

According to the Table 1, averages in the pretest and posttest of the SMTQ questionnaire indicate that the average of the two subscales confidence and control increased in the experimental group while the average of the subscale consistency in the experimental group relatively declined. However, the averages of these subscales in the control group were almost identical. 


\subsection{Inferential Analyses}

Table 2. Results of multivariate analysis for SMTQ questionnaire

\begin{tabular}{|c|c|c|c|c|c|c|}
\hline Effect & & Value & $\mathrm{F}$ & Hypothesis df & Error df & Sig. \\
\hline group & Wilks' Lambda & 0.68 & $22.66^{b}$ & 3.0 & 147.0 & 0.00 \\
\hline
\end{tabular}

According to the results in the Table 2, the effect of experimental group (wilks' Lambda $=0.68, \mathrm{~F}_{(3,147)}=22.66$, $\mathrm{p}=0.00$ ) was reported significant.

According to the results in the Table 3, the effect of experimental group (wilks' Lambda $=0.68, \mathrm{~F}_{(3,147)}=22.66$, $\mathrm{p}=0.00$ ) was reported significant.

Table 3. Results of multivariate analysis for SMTQ questionnaire

\begin{tabular}{|c|c|c|c|c|c|c|}
\hline Effect & & Value & $\mathrm{F}$ & Hypothesis df & Error df & Sig. \\
\hline group * type & Wilks' Lambda & 0.97 & $2.46^{\mathrm{b}}$ & 3.0 & 147.0 & 0.04 \\
\hline
\end{tabular}

Based on the results of multivariate analysis (see Table 3). There is a significant interaction between group and types of sports (wilks' Lambda $=0.97, \mathrm{~F}_{(3,147)}=2.46, \mathrm{p}<0.05$ ).

Table 4. Results of multivariate analysis for SMTQ questionnaire

\begin{tabular}{lllllll}
\hline Effect & & Value & F & Hypothesis df & Error df & Sig. \\
\hline group * gender & Wilks' Lambda & 0.97 & $1.21^{\mathrm{b}}$ & 3.0 & 147.0 & 0.30 \\
\hline
\end{tabular}

As can be seen in Table 4, there is no significant interaction between experimental group and gender as P-value exceeds 0.05 (wilks' Lambda $=0.976, \mathrm{~F}_{(3,147)}=1.21, \mathrm{p}<0.05$ ). This means that the MTP is not effective in changing the mental toughness based on gender in this research.

\section{Discussion}

MTP was effective in changing the mental toughness of Tehran high school student-athletes. Those results have been proved consistent with the result of other researches carried out by Connaughton, Hanton, Jones, Wady (2008), Gucciardi, Gordon, Dimmok (2008); yet inconsistent with other studies by Horsburg, Schermer, Veselka, Vernon (2009), Nicholls, Polman, Levy, Back House (2008). That inconsistency referred back to two main reasons including measurement tools and protocol implementation conditions. The result indicated that the mental training program was not effective in changing mental toughness in Tehran high school student-athletes based on gender. Which means that mental training did not make a significant difference on the basis of gender and MTP had similar effect on both of them. Nicholles et al. (2009) concluded that male athletes show higher mental toughness than female athletes. MTP was effective in change mental toughness in different types of sports (individual and team).Nicholls et al. (2009) was the first researchers, who concluded that the athletes of team sports enjoy higher mental toughness than the athletes of individual sports. This is consistent with the findings of Vealy (1988),who believes that the athletes of team sports enjoy higher self-confidence than the athletes of individual sports. According to Clough et al. (2002), self-confidence is the key element of mental toughness. Those studies are compatible with the studies of Jalili et al. (2011), who believed that there is a significant difference between the quality of mental toughness in the athletes of individual and team sports, in such a manner that the athletes of team sports enjoy higher mental toughness than the athletes of individual sports and so is the control components in the athletes of team sports.

\section{Acknowledgements}

It has been years that mental toughness and coping strategies have drawn American researchers' and planners' attention (Cohen, 2013). Moreover Gould et al. (1993) argued that adolescent are just like adults, and need to have strategies to deal with stress. Therefore, it is recommended that mental training material be included in teenagers' athletic training program in addition to physical training to be gradually accepted as an ordinary and common training program. 
Sport professionals are directly communicating with student athletes, so it is necessary that they be informed of the consequences of their speech and behavior in the minds of the teenage student athletes. As Cohen (2013) stated, unfortunately most coaches and athletes are unfamiliar with sport psychology and educational mental skills. Also, Weinberg and Gould (2003) included that some coaches and athletes do not understand how to practice and teach mental skills. The families of teenage athletes be familiar with mental training and be involved in the process. We, as researchers, can also play an effective role in the education of sport psychology to all. Thus, we have to take steps toward interaction with mass media by delivering them the results of our researches.

\section{References}

Allen, M. S., Greenlees, I., \& Jones, M. V. (2011). An investigation of the five-factor model of personality and coping behavior in sport. Journal of Sports Sciences, 29(8), 841-850. http://dx.doi.org/10.1080/02640414. 2011.565064

Anshel, M. H. (2008). Sport psychology: From Theory to practice (4th ed.). San Francisco, CA: Benjamin Cummings.

Anshel, M. H., Kim, K. W., Kim, B. H., Chang, K. J., \& Eom, H. J. (2001). A model for coping with stressful events in sport: Theory, application, and future directions. International Journal of Sport Psychology, 32, 43-75.

Clough, P., \& Strycharczyk, D. (2012). Developing mental toughness: Improving performance, wellbeing and positive behavior in others. London: Kogan page.

Clough, P., Earle, K., \& Sewell, D. (2002). Mental toughness: The concept and its measurement. In I. Cockerill (Ed.), Solutions in sport psychology (pp. 32-46). London: Thomson Learning.

Cohen, P. (2009). The fearless athlete. Digital download version. Peak performance sport center. U.S.A

Cohen, P. (2013). 10 costly mental game mistakes athletes make before competition. Peak performance sport center E book. U.S.A

Connaughton, D., Hanton, S., \& Jones, G. (2010). The development and maintenance of mental toughness in the world's best performers. The Sport Psychologist, 24, 168-193.

Connaughton, D., Hanton, S., Jones, G., \& Wadey, R. (2008). Mental toughness research: Key issues in this area. International Journal of Sport Psychology, 39, 192-204. Approaches (2nd ed.). Thousand Oaks: Sage Publications.

Crust, L. (2010). Mental toughness and coping in ultra-endurance event. Athletic Insight Journal, 2(1), 35-54.

Crust, L., \& Azadi, K. (2010). Mental toughness and athletes' use of psychological strategies. European Journal of Sport Science, 10(1), 43-51. http://dx.doi.org/10.1080/17461390903049972

Dolat-Abadi, M., \& Bahram, S. (2012). The determining Factors of sport confidence among Iranian Female gymnasts. The Journal of Sport Science, 27(1), 69-78.

Etnier, J. L. (2009). Bring you is a Game: A Young Athlete's Guide to mental toughness. The University of North Carolina Press.

Freigang, D. W. (2002). The effect of psychological skills training on self-efficacy in varsity swimmers.

Golby, J., \& Sheard, M. (2006). The relationship between genotype and positive psychological development in national-level swimmers. European Psychologist, 11(2), 143-148. http://dx.doi.org/10.1027/1016-9040. 11.2.143

Gould, D., Finch, L. M., \& Jackson, S. A. (1993). Coping strategies used by national champion figure skaters. Research Quarterly for Exercise and Sport, 64, 453-468. http://dx.doi.org/10.1080/02701367. 1993.10607599

Gucciardi, D. F., Gordon, S., \& Dimmock, J. A. (2008). Towards an understanding of mental toughness in Australian football. Journal of Applied Sport Psychology, 20, 261-281. http://dx.doi.org/10.1080/10413200 801998556

Horsburgh, V., Schermer, J., Veselka, L., \& Vernon, P. (2009). A behavioral genetic study of mental toughness and personality. Personality and Individual Differences, 46(2), 100-105. http://dx.doi.org/10.1016/j.paid. 2008.09.009

Howland, J. M. (2010). Youth swimmers coping with pressures of competition: Understanding psychological characteristics and mental skills use. Boston: Boston University 
Jalili, F., Hosseini, A., \& Salehian, H. (2011). Comparison of personality dimensions, mental toughness, and social skills of female students athletes (team-individual) and non-athletes. Annals of Biological Research, 2(6), 554-560.

Jang, K. L., Livesley, W. J., Angleitner, A., Riemann, R., \& Vernon, P. A. (2002). Genetic and environmental influences on the covariance of facets defining the domains of the five-factor model of personality. Personality and Individual Differences, 33(1), 83-101. http://dx.doi.org/10.1016/S0191-8869(01)00137-4

Jin, W. (2004). Understanding "the lost following by winning": A choking process theory. Acta Psychologica Sinica, 36(5), 621-629.

Jones, G., Hanton, S., \& Connaughton, D. (2007). A framework of mental toughness in the world's best performers. The Sport Psychologist, 21, 243-264.

Kashani, V. (2010). The comparison of mental toughness in athlete men and women in individual contact and non-contact sports, at different levels of skills. Tehran: Tehran University Press.

Khanjari, Y. (2012). The effect of a course of psychological skills training program on chosen mental skills and the performance of teenager female taekwondo athletes of Iranian national team. Tehran university press.

Kristiansen, E., \& Roberts, G. C. (2010). Young elite athletes and social support: Coping with competitive and organizational stress in "Olympic Competition". Scandinavian Journal of Medicine and Science in Sports, 20(4), 680-695. http://dx.doi.org/10.1111/j.1600-0838.2009.00950.x

Martins, A., Ramalho, N., \& Morin, E. (2010). A comprehensive meta-analysis of the relationship between emotional intelligence and health. Personality and Individual Differences, 49(6), 554-564. http://dx.doi.org/ 10.1016/j.paid.2010.05.029

Navabinezhad, F. (2000). Female athletes and sport success. The Journal of Psychology and Society, 12(1), 102-111.

Nicholls, A. R., Polman, R. C., Levy, A. R., \& Backhouse, S. (2008). Mental toughness, optimism, and coping among athletes. Personality and Individual Differences, 44(5), 1182-1192. http://dx.doi.org/10.1016/j.paid. 2007.11.011

Rezvani, M. (2013). The effect of mental training program on mental toughness and sport performance in futsal players. Tehran: Beheshti university press.

Sadugh, A., \& Hamidi, K. (2011). Art Martial Success, outcomes and offers. The Journal of Sport Science, 24(1), 92.

Sanati-monfared, Sh. (2006). The effect of on metal skills of athletes participating in the Asian Games in Doha 2006. Research design in the center of Iran's National Olympic Academy.

Sheard, M. (2010). Mental toughness: The mindset behind sporting achievement. London: Rutledge.

Sheard, M., \& Golby, J. (2006). Effects of psychological skills training program on swimming performance and positive psychological development. International Journal of Sport and Exercise Psychology, 4(2), 149-169. http://dx.doi.org/10.1080/1612197X.2006.9671790

Vealey, R. S. (1988). Sport-confidence and competitive orientation: An addendum on scoring procedures and gender differences. Journal of Sport and Exercise Psychology, 10, 471-478.

Vealy, R. S. (2002). Personality and Sport behavior. In T. Horn (Ed.), Advances in Sport psychology (2nd ed., pp. 43-82). Champaign, IL: Human Kinetics. .

Weinberg, R. S., \& Gould, D. (2003). Foundations of sport and Exercise psychology. Champaign IL: Human Kinetics.

Weinberg, R. S., \& Williams, J. (2001). Integration and implementing a psychological skills peak performance (4th ed.). Mountain View, CA: Mayfield.

Weinberg, R., \& Butt, J. (2011). Coaches' views of mental toughness and how it is built. International Journal of Sport and Exercise Psychology, 9, 156-172. http://dx.doi.org/10.1080/1612197X.2011.567106

Yoo, J. (2000). Factorial validity of the coping scale for Korean athletes. International Journal of Sport Psychology, 31, 391-404.

Zandi, H., \& Menati, M. (2013). The effect of psychological skill training in mental skills and functions among young footballer. Sport Science Magazine, 28(1), 102-110. 


\section{Copyrights}

Copyright for this article is retained by the author(s), with first publication rights granted to the journal.

This is an open-access article distributed under the terms and conditions of the Creative Commons Attribution license (http://creativecommons.org/licenses/by/3.0/). 